\title{
Antibiotic resistance in Escherichia coli isolates from roof harvested rainwater tanks and urban pigeon faeces as the likely source of contamination
}

\author{
Lizyben Chidamba $^{\mathrm{a}^{*}}$ and Lise Korsten ${ }^{\mathrm{a}}$ \\ ${ }^{a}$ Department of Microbiology and Plant Pathology, University of Pretoria, Pretoria 0002, South Africa \\ *To whom all correspondence should be addressed. Phone: 0782540386 Email: lizybenc@ gmail.com
}

\begin{abstract}
The objective of this study was to investigate the risks associated with the use of roof harvested rainwater RHRW and the implication of pigeons as the most likely source of contamination by testing for antibiotic resistance profiles of E. coli. A total of 239 Escherichia coli were isolated from thirty fresh pigeon faecal samples (130 isolates), 11 RHRW tanks from three sites in Pretoria (78) and two in Johannesburg (31). In all samples, resistance to ampicillin (22.7.9\%), gentamicin (23.6\%), amikacin (24\%), tetracycline (17.4) and amoxicillin (16.9\%) were the most frequently encountered form of resistance. However, a relatively higher proportion of isolates from pigeon faeces were antibiotic resistant than those from RHRW. The highest number of phenotypes was observed for single antibiotics and no single antibiotic resistance was observed for chloramphenicol, ceftriaxone, gentamicin, cefoxitin, cotrimoxazole, although they were detected in multiple antibiotic resistance (MAR) phenotypes. The highest multiple antibiotic resistance (MAR) phenotypes were observed for a combination of four antibiotics, on isolates from JHB (18.8\%), pigeon faeces (15.2\%) and Pretoria (5.1\%). The most abundant resistance phenotype to four antibiotics, Ak-Gm-Cip-T was dominated by isolates from pigeon faeces (6.8\%) with Pretoria and Johannesburg isolates having low proportions of $1.3 \%$ and $3.1 \%$, respectively. Future studies should target isolates from various environmental settings in which rainwater harvesting is practiced and the characterisation of the antibiotic resistance determinant genes among the isolates.
\end{abstract}

Keywords: Antibiotic resistance, E. coli, rainwater harvesting, contamination, pigeon faeces 


\section{Introduction}

South Africa has a mix of developed and developing regions with at least 9.7 million (20\%) of the people not having access to adequate water supply (Kahinda et al. 2007). RHRW appears to be one of the most promising alternatives for supplying freshwater in the face of increasing water scarcity and escalating demand (Sazakli et al. 2007). Rainwater harvesting (RHRH) can provide water directly to households including those in rural and peri-urban areas where conventional technologies cannot supply. In order to improve water access, the South African government has committed itself to provide RHRW tanks to poor households, who in most instances use it without prior treatment as it is assumed to be safe ((Kahinda et al. 2007). Although rainwater is generally considered clean, the potential of public health risk associated with the presence of pathogenic microorganisms cannot be ignored (Ahmed et al. 2011a; Ahmed et al. 2011b). Faeces of wild birds, insects, mammals, and reptiles that have access to the roof can be washed into the holding tank during rain events. Consequently, contamination of harvested rainwater by enteric bacteria including faecal coliforms, Escherichia coli, and enterococci spp which are commonly found in the guts of warm blooded animals has been reported (Sung et al. 2010; Young et al. 2010; Ahmed et al. 2011a). These bacteria have a wide natural host range, which includes all warm blooded animals, some cold-blooded animals, and environmental reservoirs, such as sediments and free-living strains (Harwood et al. 1999; Power et al. 2005)

Although several enteric bacteria can be used to monitor faecal contamination, E. coli is the most used indicator bacteria as well as a regulatory organism of faecal pollution in aquatic environments (Clesceri et al. 1998). Escherichia coli density at elevated levels, primarily provide evidence of faecal pollution and secondarily reflect the possible presence of bacterial, viral and parasitic enteric pathogens (Mohapatra et al. 2007). However, current E. coli enumeration standard methods do not provide information on potential sources of faecal pollution. Determining the sources of origin of faecal contamination is commonly referred to as bacterial source tracking (BST) and is commonly used to assess the degree of public health risk and to ensure the development of specific approaches to reduce faecal contamination and the associated pathogens responsible for water- borne disease transmission (U.S. Environmental Protection Agency 2002). 
Several methods of bacterial source tracking (BST) have been developed in which sources of microbial contamination are identified according to differences in the characteristics of bacteria from different animal faeces. Hence, an increased understanding of the genetic variability of populations in animal reservoirs and rainwater tanks can inform epidemiological studies. Several genotypic and phenotypic BST methods have been developed in recent years to identify sources of faecal pollution (Myoda et al. 2003; Mohapatra and Mazumder 2008). Probable source(s) of faecal pollution are identified by comparing the fingerprints (phenotypic or genotypic profiles) of the environmental E. coli isolates with a reference library consisting of the fingerprints of E. coli obtained from known sources of faecal pollution (Anyadike and Obeta 2012).

Genotypic BST methods consider the host-specific genetic differences of indicator organisms for example ribotyping, Pulsed field gel electrophoresis (PFGE), randomly amplified polymorphic DNA (RAPD) and repetitive palindromic DNA sequences (Rep PCR) (Dallacosta et al. 1998; Zulkifli et al. 2009; Goering 2010; Sheludchenko 2011). Phenotypic methods employ host-specific biochemical properties, for example antibiotic resistance profiling and carbon source utilisation tests (Anderson et al. 2006; Stefanowicz 2006).

Concerns with the emergence of antibiotic resistant bacteria have been raised over the contamination of surface waters from livestock operations and human septage. Resistant bacteria have been isolated from a variety of sources, including domestic sewage, drinking water, rivers, and lakes (Antai 1987; Meays et al. 2004; Donovan et al. 2008; Kinge et al. 2010). Faecal strains of E. coli resistant to antibiotics have been found at various prevalence levels in wild bird populations. In particular, bird populations common to areas inhabited by people and areas with a high density of livestock have been reported to be colonised with antibiotic resistant $E$. coli strains possibly selected for by the antibiotic practices in humans and domestic animals (Silva et al. 2009).

Urban birds especially pigeons and doves coexist with humans in urban environments and are considered to be important reservoirs and vectors of pathogenic and antibiotic resistant bacterial strains (Radimersky et al. 2010). The adaptation of these birds to urban environments is mainly ascribed to (i) the architecture of urban constructions which have gaps, cracks and spaces that can be used for landing, nesting and shelter, protecting the birds 
from the weather; (ii) the absence of natural predators; and (iii) availability of food (Silva et al. 2009)(Silva et al., 2012). Animal feed lots including those for dairy cows and chicken feed waste provide an abundant source of food to the birds which then multiply extensively and become a significant source of faecal pollution. The transmission of infectious diseases or antibiotic resistant strains usually happens by either ingestion of food, water, handling of products contaminated with their faeces and dispersion of wind-dried pigeon droppings (Marques et al. 2007).

Although there have been several researches on surface and ground water contamination by antibiotic resistant bacteria, literature on antibiotic resistant bacteria in roof harvested rainwater is scarce (Antai 1987; Meays et al. 2004; Donovan et al. 2008; Kinge et al. 2010). In rainwater harvesting, urban birds are a major source of faecal contamination as they have direct access to the roof catchment surface and have been implicated as reservoirs and vectors for the spread of antibiotic resistant strains of $E$. coli (Radimersky et al. 2010). Resistance to more than one antibiotic by a single bacterial isolate is commonly reported. Consequently, resistance to multiple antibiotics have been used to identify and differentiate $E$. coli strains from different animal species (Dolejska et al. 2008). The use of antibiotic resistance profiles is simple, cost-effective, and suitable for surveillance and has been used for E. coli strains to identify sources of faecal contamination in water (Kinge et al. 2010).

To help evaluate the risk associated with the use of RHRW and the significance of pigeon faeces as the most likely source of contamination, we characterised antibiotic resistance profiles in E. coli isolated from RHRW tanks and urban pigeon faeces. The isolates originated from faeces of urban pigeons (Columbia livia), and RHRW obtained from Johannesburg and Pretoria in Gauteng Province of South Africa. Sampling sites could be categorised into farm and urban settings, and urban settings could be divided into low and high density suburbs. The objective of this study was to evaluate the prevalence of antibiotic resistance and compare antibiotic resistance profiles of $E$. coli isolated from pigeon faeces and RHRW from different environmental settings. 
The motivation for this was the fact that previous studies on RHRW have implicated droppings of birds, mammals and/or rodents that have access to catchment areas or water storage tanks as the possible sources of microbial contamination (Sivanappan 2006; Ahmed et al. 2011a). Of these animals birds are the most mobile and have been implicated as reservoirs of antibiotic resistant enteric pathogens (Silva et al. 2009).

\section{Methodology}

\section{Area of the study and collection of samples}

Roof harvested rainwater samples were collected from five sampling sites which included, three in Pretoria (PTA); the Experimental Farm, University of Pretoria Experimental Farm (PTA Site 1(S1)), the Plant Science Building, University of Pretoria Hatfield campus (PTA Site 2 (S2) and a house in Sunnyside suburb (PTA Site 3 (S3), and two sites in Johannesburg (JHB); Endluweni Primary School (JHB S1) and Thembisa Secondary School (JHB S2). Faecal samples were collected from urban pigeons (Columbia livia) at the University of Pretoria Experimental Farm only. This site (PTA S1) represents a typical farm setting; with cattle feed pen within $100 \mathrm{~m}$, where a large number of pigeons come to feed. These pigeons also feed on chicken layers waste from fowl runs approximate $800 \mathrm{~m}$ away. The house where three rainwater tanks are installed (PTA S1) has overhanging Mulberry trees on the roof, where various kinds of birds feed on mulberries. The Plant Science Building site (PTA S2) is located at the University of Pretoria Main Campus. This site is on the second floor and has three tanks installed. The site represents a typical urban scenario where there is minimal vegetation and bird interference. The PTA S3 is located in Sunnyside suburb in Pretoria. This site is surrounded by trees where various kinds of birds nest. The Johannesburg sites (JHB S1and JHB S2) are schools (each with two rainwater tanks) located in Thembisa, a high density suburb with limited number of trees and various birds which feed on garbage dumps.

\section{Sample collection and isolation of presumptive Escherichia coli strains}

Rainwater Sample collection

Samples were collected from eleven rainwater tanks during the 2012 - 2013 rain seasons, from September to February within 1 to 4 days after a rain event (ranging from 35 to 130 
$\mathrm{mm}$ ) as previously described by (Ahmed et al. 2008). In total 74 RHRW samples (of which forty-four tested positive to $E$. coli) were collected in duplicates from the outlet taps located close to the base of the tanks, in sterilised two litre containers. Taps were wiped with $70 \%$ ethanol, and allowed to run for 30 to 60 seconds to flush out stagnant water from the taps before collecting water samples. Collected samples were transported to the laboratory and processed within 10 hours.

Undiluted RHRW samples were assayed directly for densities of faecal coliforms and E. coli, with Colilert chromogenic substrate tests kits and Quantitray 2000 MPN trays (Idexx, Westbrook, Maine) as per the manufacturer's instructions. The inoculated Quantitrays were subsequently sealed and incubated at $35^{\circ} \mathrm{C}$ for $24-28 \mathrm{~h}$. Following incubation, the Quantitray wells were read for yellow colour and fluorescence. A bench top ultraviolet (UV) light (366 $\mathrm{nm}$ ) was used to identify fluorescent wells. A manufacturer provided MPN table (Idexx, Westbrook, Maine) was used to generate microbial density estimates based on the proportion of positive reactions in each tray.

Faecal sample collection

Fresh faeces from thirty birds including pigeons and doves were collected. Indicator bacterial density in faecal material was measured by first diluting one gram of faeces in $9 \mathrm{~m} \ell$ of distilled water, vortexed and allowed to stand for 5 minutes to allow debris to settle. A $1 \mathrm{~m} \ell$ sample of the supernatant was consequently extracted and serially diluted for microbial isolation and quantification. Densities of faecal coliforms and E. coli, and enterococci were determined with Colilert-18 as described above.

\section{Recovery}

Following incubation, the backing material of each Quantitray was disinfected by application of $70 \%$ ethanol with a sterile swab. After the residual ethanol had evaporated, sterile razor blades were used to pierce the backing material of three fluorescence positive wells per tray and three trays were processed per water sample. One loop full of well content was streaked onto mEndo selective agar for the isolation of E. coli. Presumptive E. coli colonies were subcultured twice on nutrient agar and re-inoculated into the respective collilert chromogenic 
media in sterile 96 micro well plates and incubated for 18 hours to confirm fluorescence before MALDI-TOF-MS and PCR analysis.

\section{MALDI-TOF-MS identification and characterisation of bacterial isolates}

Bacterial strains were sub-cultured twice on nutrient agar (Merck, Johannesburg) before MALDI-TOF-MS analysis. After 24 to 48-hour cultivation of an isolate on nutrient agar, a single colony was transferred with a toothpick onto MALDI plates in duplicates (SigmaAldrich, USA). The preparation was overlaid with $1 \mu \ell$ of saturated solution of cyano-4hydroxycinnamic acid in organic solution (50\% acetonitrile, $2.5 \%$ trifluoroacetic acid), crystallised by air-drying at room temperature and directly screened (Bittar et al. 2009; Pinto et al. 2011). Mass spectra were generated with the Microflex LT mass spectrometer operated by the MALDI Biotyper automation control and recorded by Flex Control software (Bruker Daltonics, Bremen, Germany). Three hundred shots per sample spot were acquired using the recommended instrument settings for bacterial identification (linear positive mode, $60 \mathrm{~Hz}$ laser frequency, $20 \mathrm{kV}$ acceleration voltage, $16.7 \mathrm{kV}$ IS2 voltage, $170 \mathrm{~ns}$ extraction delay, and 2,000 to $20,137 \mathrm{~m} / \mathrm{z}$ range). The peak lists generated was used for matches against the reference library directly using the integrated pattern matching algorithm of the software. The whole process from MALDI-TOF-MS measurement for identification was performed automatically without user intervention.

MALDI Biotyper 3.0 software (Bruker Daltonics) was used to analyse raw spectra of the bacterial isolates with default settings. The software compares acquired sample spectra to reference spectra in the provided database and compiles a list of best matching database records. The degree of spectral pattern matching is expressed as a logarithmic identification score and interpreted according to the manufacturer's instructions. Results are expressed as $\log$ (score) values ranging from 0 to 3 levels. Scores $\geq 2.300$ indicate species identification with a high level of confidence, $\geq 2.000$ indicate species identification, $<1.700-1.999$ indicate genus identification, and >1.700, no identification (Romanus et al. 2011) . 


\section{Polymerase chain reaction for detection of UidA gene in Escherichia coli}

The polymerase chain reaction (PCR) was used to detect the presence of the Uid gene, which codes for the $\beta$-D-glucuronidase enzyme. A 147 bp coding region of the E. coli uid gene was amplified using the 20 and 21-mer primers UAL-754 (5'-AAAACGGCAAGAAAAAGCAG-3') and UAR-900 (5'-ACGCGTGGTTACAGTCTTGCG-3') (Bej et al., 1991). These primers were synthesised by Inqaba Biotech (Pretoria, South Africa). An ICycler thermal cycler (Bio-Rad, UK) was used to amplify the DNA. In both PCRs the final reaction volume of $25 \mu 1$ consisted of $12.5 \mu 1$ double strength PCR master mix $(0.05 \mathrm{U} / \mu 1$ Taq DNA Polymerase in reaction buffer, $0.4 \mathrm{mM}$ of each dNTP (dATP, dCTP, dGTP, dTTP), 4mM $\mathrm{MgCl}_{2}$; (Fermentas Life Science, US), PCR-grade water (Fermentas Life Science, US), 50ng sample DNA and 25pmole of each primer. Amplification was performed with a thermal cycler programmed for 1 cycle of $2 \mathrm{~min}$ at $94{ }^{\circ} \mathrm{C} ; 25$ cycles of $1 \mathrm{~min}$ at $94{ }^{\circ} \mathrm{C}, 1 \mathrm{~min}$ at $58{ }^{\circ} \mathrm{C}, 2$ min at $72{ }^{\circ} \mathrm{C} ; 1$ cycle of $5 \mathrm{~min}$ at $72{ }^{\circ} \mathrm{C}$. PCR products were electrophoresed on a $1.5 \%$ agarose gel, stained with GR Green (Fermentas Life Science, USA), and visualised using Gel Documentation System (Bio-Rad Gel Doc EZ Imager, USA).

\section{Antimicrobial susceptibility testing}

The Kirby-Bauer disk diffusion technique was used to determine antibiotic susceptibility profiles of $239 \mathrm{E}$. coli isolates. Isolates were cultured at $37^{\circ} \mathrm{C}$ for 24 hours in nutrient broth (Merck, Johannesburg, South Africa) and the suspension was adjusted to a turbidity equivalent to a $0.5 \mathrm{McFarland}$ standard before spreading $100 \mu \mathrm{l}$ onto Mueller Hinton agar plate (Merck, Johannesburg, South Africa). The disks used (Mast Diagnostics, UK, supplied by Davies Diagnostics, Midrand, SA) included ampicillin (Ap, $10 \mu \mathrm{g})$, amoxicillin (A, $\mu \mathrm{g} 10)$,

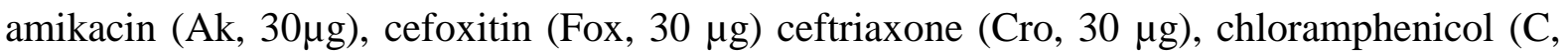

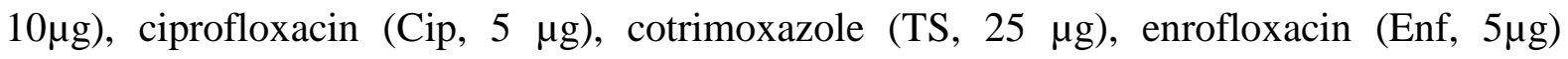
gentamicin $(\mathrm{Gn}, 10 \mu \mathrm{g})$, nalidixic acid $(\mathrm{Na}, 30 \mu \mathrm{g})$ and tetracycline $(\mathrm{T}, 30 \mu \mathrm{g})$ are shown in Table 1. Isolates were categorised as susceptible or resistant based upon interpretive criteria developed by the CLSI, 2007). 
Table 1: Details of the antibiotics that were used in the study to test for antibiotic resistance

\begin{tabular}{|c|c|c|c|c|c|c|}
\hline \multirow[b]{2}{*}{ Group } & \multirow[b]{2}{*}{ Antibiotic } & \multirow[b]{2}{*}{$\begin{array}{l}\text { Abbrevi } \\
\text { ation }\end{array}$} & \multirow[b]{2}{*}{$\begin{array}{l}\text { Antibiotic disc } \\
\text { concentrations } \\
\qquad(\mu \mathrm{g})\end{array}$} & \multicolumn{3}{|c|}{ Inhibition zone (mm) } \\
\hline & & & & Resistant & $\begin{array}{l}\text { Intermediate } \\
\text { resistant }\end{array}$ & $\begin{array}{c}\text { Susce } \\
\text { ptibl } \\
\text { e }\end{array}$ \\
\hline \multirow[t]{2}{*}{ Penicillin's } & Ampicillin & A & 10 & $\leq 13$ & $14-16$ & $\geq 17$ \\
\hline & Amoxicillin & AP & 10 & $\leq 13$ & $14-16$ & $\geq 17$ \\
\hline \multirow[t]{2}{*}{ Aminoglycosides } & Amikacin & AK & 30 & $\leq 14$ & $15-16$ & $\geq 17$ \\
\hline & Gentamicin & GM & 10 & $\leq 12$ & $13-14$ & $\geq 15$ \\
\hline \multirow[t]{2}{*}{ Quinolones } & Enrofloxacin & ENF & 5 & $\leq 17$ & $18-20$ & $\geq 21$ \\
\hline & Cefoxitin & FOX & 30 & $\leq 14$ & $15-17$ & $\geq 18$ \\
\hline Phenicols & Chloramphenicol & $\mathrm{C}$ & 10 & $\leq 12$ & $13-17$ & $\geq 18$ \\
\hline Ciprofloxacin & Ciprofloxacin & CIP & 5 & $\leq 15$ & $16-20$ & $\geq 21$ \\
\hline Cephems & Ceftriaxone & CRO & 30 & $\leq 13$ & $14-20$ & $\geq 21$ \\
\hline Quinolones & Nalidixic acid & NA & 30 & $\leq 13$ & $14-18$ & $\geq 19$ \\
\hline $\begin{array}{l}\text { Folate Pathway } \\
\text { Inhibitors }\end{array}$ & Cotrimoxazole & TS & 25 & $\leq 10$ & $11-15$ & $\geq 16$ \\
\hline Tetracyclines & Tetracycline & $\mathrm{T}$ & 30 & $\leq 11$ & $12-14$ & $\geq 15$ \\
\hline
\end{tabular}

Source: The concentration used as well as the inhibition zone measurements were according to the National

Committee on Clinical Laboratory Standards (CLSI, 2007)

Note: The abbreviations are as they appeared on the antibiotic discs.

\section{Statistical analysis}

All statistical analysis were carried out using Statistica 10 (Stat soft, US). Data for the antimicrobial agent resistance of each bacterial isolate were reported in two formats: either as the diameter of the zone of inhibition (in millimetres) or as susceptible or resistant (based on CLSI breakpoints). Since these data were used to evaluate the grouping isolates by their geographical origin (i.e. by sites within specific areas) and by their source (i.e. RHRW or pigeon faeces). RHRW isolates were handled in 2 different ways, (i) individually by site (PTA S1, PTA S2, PTA S3, JHB S1 and JHB S2), by groups based on area (PTA or JHB) and source (RHRW). Associations between isolate source groups, RHRW areas and sites, and associated antimicrobial agent profile (resistant or not resistant) were expressed as percentages. The significance of differences in zones of inhibition between species groups was calculated with the Kruskal Wallis test (alpha value, 0.05) and the Pearson product moment correlation was used to compare the similarity relationship between the groups. 
Susceptibility data on the E. coli isolates from the different sites and sources tested againt the twelve antibiotics, were used for cluster analysis by means of Ward's method and Euclidean distances as a measure of similarity. Ward's clustering method is a hierarchical agglomerative method whose objective is to create clusters that give minimum increase in the total within group error sum of squares (Ward, 1963).

\section{Results}

A total of thirty faecal samples from urban pigeons (Columbia livia) from Pretoria and seventy-four RHRW samples from eleven rainwater tanks in Johannesburg (4) and Pretoria (7) were collected. We detected E. coli from all pigeon faeces and RHRW sites, although only forty-four of the 74 RHRW samples tested were positive for E. coli. Generally, levels of RHRW contamination with $E$. coli were relatively higher in water samples obtained from PTA S1 and PTA S3 than the rest of the RHRW sites. Data on the prevalence and abundance of enteric microbial populations are reported in chapter 4. Table 3 shows the number of isolates that were used in this study and their respective sources. A total of 328 presumptive E. coli isolates were isolated from both pigeon droppings and RHRW samples, sub-cultured and further analysed. However, only 239 isolates satisfied all the identification criteria and were used for subsequent analysis. The 239 isolates were comprised of 130 isolates from pigeon faeces, 78 from Pretoria and thirty-one from Johannesburg. Isolates from Pretoria sites were comprised of 10, 18 and 50 isolates from PTA S3, PTA S2 and PTA S1 whereas those from Johannesburg were from JHB S2 (10) and JHB S1 (21).

\section{Antibiotic susceptibility}

All 239 E. coli isolates were subjected to antibiotic susceptibility tests with twelve antimicrobial agents, from ten different antibiotic classes (Table 1). Antibiotic resistance was detected in both pigeon droppings and RHRW E. coli isolates (Table 2). The most frequently encountered form of resistance in all samples was resistance to ampicillin In all samples, resistance to ampicillin (22.7.9\%), gentamicin (23.6\%), amikacin (24\%), tetracycline (17.4) and amoxicillin (16.9\%) were the most frequently encountered form of resistance. However, a relatively higher proportion of isolates from pigeon faeces were antibiotic resistant than those from RHRW tanks, with the most significant differences being noted in resistance to 
gentamicin (12.3\%), tetracycline (9.8\%), chloramphenicol (6.5\%) and amikacin (4.2\%). Pigeon droppings and RHRW E. coli isolates exhibited resistance to eleven of the twelve antibiotics tested, with cotrimoxazole resistance not being detected in bird samples and ceftriaxone resistance in RHRW samples. Other forms of resistance detected in small proportions were on ceftriaxone (1.5\%) and nalidixic acid (3.8\%) in pigeon droppings and cotrimoxazole $(0.9 \%)$, nalidixic acid $(0.9 \%)$ chloramphenicol $(1.8 \%)$ ciprofloxacin $(3.7 \%)$, cefoxitin $(3.7 \%)$ and ciprofloxacin (4.6\%) in RHRW samples.

Table 2: Antibiotic resistance profiles of Escherichia coli isolated from roof harvested rainwater originating from Pretoria and Johannesburg, and bird faecal samples in Gauteng Province of South Africa

\begin{tabular}{|c|c|c|c|c|c|c|c|c|c|c|c|c|c|c|c|c|c|}
\hline \multirow{3}{*}{ Antibiotic } & \multirow{3}{*}{$\begin{array}{l}\text { Symbo } \\
1\end{array}$} & \multicolumn{10}{|c|}{ RHRW Sources } & \multirow{2}{*}{\multicolumn{2}{|c|}{ RHRW $^{\mathrm{a}}$}} & \multirow{2}{*}{\multicolumn{2}{|c|}{ Bird }} & \multirow{2}{*}{\multicolumn{2}{|c|}{ Totals }} \\
\hline & & \multirow{2}{*}{\multicolumn{2}{|c|}{ JHB S1 }} & \multicolumn{2}{|c|}{ JHBS } & \multicolumn{2}{|c|}{ PTAS } & \multicolumn{2}{|c|}{ PTAS1 } & \multicolumn{2}{|c|}{ PTA } & & & & & & \\
\hline & & & & $n$ & $\%$ & $n$ & $\%$ & $n$ & $\%$ & $n$ & $\%$ & $n$ & $\%$ & $n$ & $\%$ & $n$ & $\%$ \\
\hline Amoxicillin & A & 2 & 9.5 & - & - & 2 & 20 & 1 & 2 & 3 & 16. & 2 & 18. & 2 & 15. & 4 & 16. \\
\hline Amikacin & $\mathrm{AK}$ & 9 & 42. & 1 & 10 & - & - & 1 & 2 & 4 & $\overline{2} 2$. & $\hat{2}$ & $\hat{22}$ & 3 & 27. & 6 & 24. \\
\hline Ampicillin & AP & 1 & 4.8 & 2 & 20 & 1 & 10 & 1 & 2 & 5 & 27. & $\stackrel{A}{2}$ & 18. & 3 & 26. & $\hat{5}$ & 22. \\
\hline Chloramphenic & $\mathrm{C}$ & 1 & 4.8 & - & - & - & - & - & 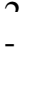 & 1 & $\begin{array}{l}\text { o } \\
5.6\end{array}$ & $\hat{2}$ & $\begin{array}{l}2 \\
1.8\end{array}$ & $\begin{array}{l}5 \\
1 \\
2\end{array}$ & $\begin{array}{l}2 \\
9\end{array}$ & $\overline{1}$ & $\overrightarrow{5} .8$ \\
\hline Ciprofloxacin & CIP & 1 & 4.8 & - & - & 1 & 10 & 1 & 2 & - & - & 3 & 2.8 & $\begin{array}{l}1 \\
n\end{array}$ & 7.5 & 1 & 5.4 \\
\hline Ceftriaxone & $\mathrm{CRO}$ & - & - & - & - & - & - & - & - & - & - & - & - & 2 & 1.5 & 2 & 0.8 \\
\hline Enrofloxacin & ENF & 4 & 19 & - & - & - & - & - & - & - & - & 4 & 3.7 & 8 & 6 & 1 & 5 \\
\hline Cefoxitin & FOX & 1 & 4.8 & - & - & - & - & 3 & 6 & - & - & 4 & 3.7 & 7 & 5.3 & 1 & 4.5 \\
\hline Gentamicin & GM & 6 & 28. & 3 & 30 & - & - & $\begin{array}{l}1 \\
n\end{array}$ & $\begin{array}{l}2 \\
n\end{array}$ & 2 & 11. & $\begin{array}{l}2 \\
1\end{array}$ & $\begin{array}{l}19 . \\
2\end{array}$ & $\begin{array}{l}3 \\
6\end{array}$ & 27. & $\begin{array}{l}\hat{5} \\
7\end{array}$ & 23. \\
\hline Nalidixic Acid & NA & - & - & - & - & - & - & 1 & 2 & - & - & 1 & 0.9 & 6 & 4.5 & 7 & 2.9 \\
\hline Tetracycline & $\mathrm{T}$ & 6 & $\begin{array}{l}28 . \\
a\end{array}$ & 1 & 10 & - & - & 2 & 4 & 4 & $\begin{array}{l}22 . \\
?\end{array}$ & $\begin{array}{l}1 \\
2\end{array}$ & $\begin{array}{l}11 . \\
n\end{array}$ & $\begin{array}{l}2 \\
\Omega\end{array}$ & $\begin{array}{l}21 . \\
o\end{array}$ & $\begin{array}{l}4 \\
-\end{array}$ & 17. \\
\hline Cotrimoxazole & $\mathrm{TS}$ & 1 & 4.8 & - & - & - & - & - & - & - & - & 1 & 0.9 & 3 & 2.3 & 4 & 1.7 \\
\hline
\end{tabular}

Note: Percentages were calculated by dividing the number of E. coli isolates confirmed as antibiotic resistant in a particular sample site by the total number of isolates tested for the particular site or group.

${ }^{\mathrm{a}}$ All rooftop harvested rainwater sites (RHWR) 


\section{Non-parametric test}

Kruskal Wallis test was performed on original disk diffusion zone sizes data with respect to the different sources for each antibiotic tested (Table 3). The results showed that antibiotic resistance/susceptibility patterns were significantly different for nine of the twelve antibiotics tested, with no significant differences being detected for the three antibiotics; amoxicillin, ampicillin and ceftriaxone. Since the Kruskal Wallis test leads to significant results, when at least one of the samples is different from the other samples but does not identify where the differences occur or how many differences actually occur. We further compared rainwater sample sources only and significant differences $(p \leq 0.05)$ were observed on resistance to ampicillin only. This implies that the source of significant differences were pigeon faecal samples for 8 of the nine antibiotics. Consequently, the largest inhibition zones (indicating greater susceptibility) were found in RHRW sources for eight of the antibiotics on which significant differences had been observed (Figure 1). When resistance to ampicillin among RHRW sites was considered significantly larger inhibition zones were found with JHB S1 compared to the rest of the other sources (Table 3).

Table 3: Kruskal Wallis test of differences between pigeon and roof harvested rainwater isolate sources

\begin{tabular}{|c|c|c|c|c|c|c|c|c|}
\hline \multirow{3}{*}{$\frac{\text { Antibiotics }}{\text { Amoxicillin }}$} & \multicolumn{6}{|c|}{ Mean disk diffusion zone diameter (mm) } & \multirow{2}{*}{\multicolumn{2}{|c|}{$\begin{array}{c}\text { Kruskal Wallis } \\
(P \text {-value }) \\
\text { All Sources RHRW }^{\mathrm{b}}\end{array}$}} \\
\hline & \multirow{2}{*}{$\begin{array}{l}\begin{array}{l}\text { Bird } \\
(\mathrm{n}=130)\end{array} \\
15.2\end{array}$} & \multirow{2}{*}{$\begin{array}{l}\begin{array}{l}\text { JHB S1 } \\
(\mathrm{n}=21)\end{array} \\
16.7\end{array}$} & \multirow{2}{*}{$\begin{array}{l}\text { JHB S2 } \\
(\mathrm{n}=10) \\
17.5\end{array}$} & \multirow{2}{*}{$\begin{array}{l}\begin{array}{l}\text { PTA S3 } \\
(\mathrm{n}=10)\end{array} \\
14.8\end{array}$} & \multirow{2}{*}{$\begin{array}{l}\begin{array}{l}\text { PTA S2 } \\
(\mathrm{n}=18)\end{array} \\
15.6\end{array}$} & \multirow{2}{*}{$\begin{array}{l}\begin{array}{l}\text { PTA S1 } \\
(\mathrm{n}=50)\end{array} \\
14.8\end{array}$} & & \\
\hline & & & & & & & .115 & .196 \\
\hline Amikacin & 16.9 & 17.2 & 17.9 & 18.9 & 18.1 & 18.3 & .249 & .717 \\
\hline Ampicillin & 15 & 17 & 14.6 & 15.1 & 14.9 & 14.9 & .054 & .041 \\
\hline Chloramphenicol & 16.8 & 17.8 & 17.7 & 18.4 & 18.3 & 18.5 & .000 & .895 \\
\hline Ciprofloxacin & 25.8 & 29.3 & 28.5 & 29.4 & 30.6 & 31.6 & .000 & .466 \\
\hline Ceftriaxone & 25 & 25.1 & 26.2 & 25.9 & 25.9 & 25.5 & .789 & .928 \\
\hline Enrofloxacin & 24.1 & 24.6 & 28.2 & 26.2 & 26.9 & 26.2 & .001 & .464 \\
\hline Cefoxitin & 20.2 & 21 & 22 & 21 & 21.2 & 21 & .006 & .921 \\
\hline Gentamicin & 15.6 & 16.3 & 16 & 16.9 & 17.3 & 17.7 & .037 & .653 \\
\hline Nalidixic Acid & 18.3 & 19.3 & 20 & 20.2 & 20.2 & 19.4 & .002 & .397 \\
\hline Tetracycline & 14.7 & 14.5 & 17.2 & 16.1 & 15.1 & 16.7 & .053 & .127 \\
\hline Cotrimoxazole & 19.8 & 20.7 & 22.6 & 21.8 & 22.2 & 21.2 & .001 & .694 \\
\hline
\end{tabular}

Significance level at $p \leq 0.05,{ }^{\text {a }}$ tests among all isolate sources, ${ }^{b}$ tests among RHRW sources only. 

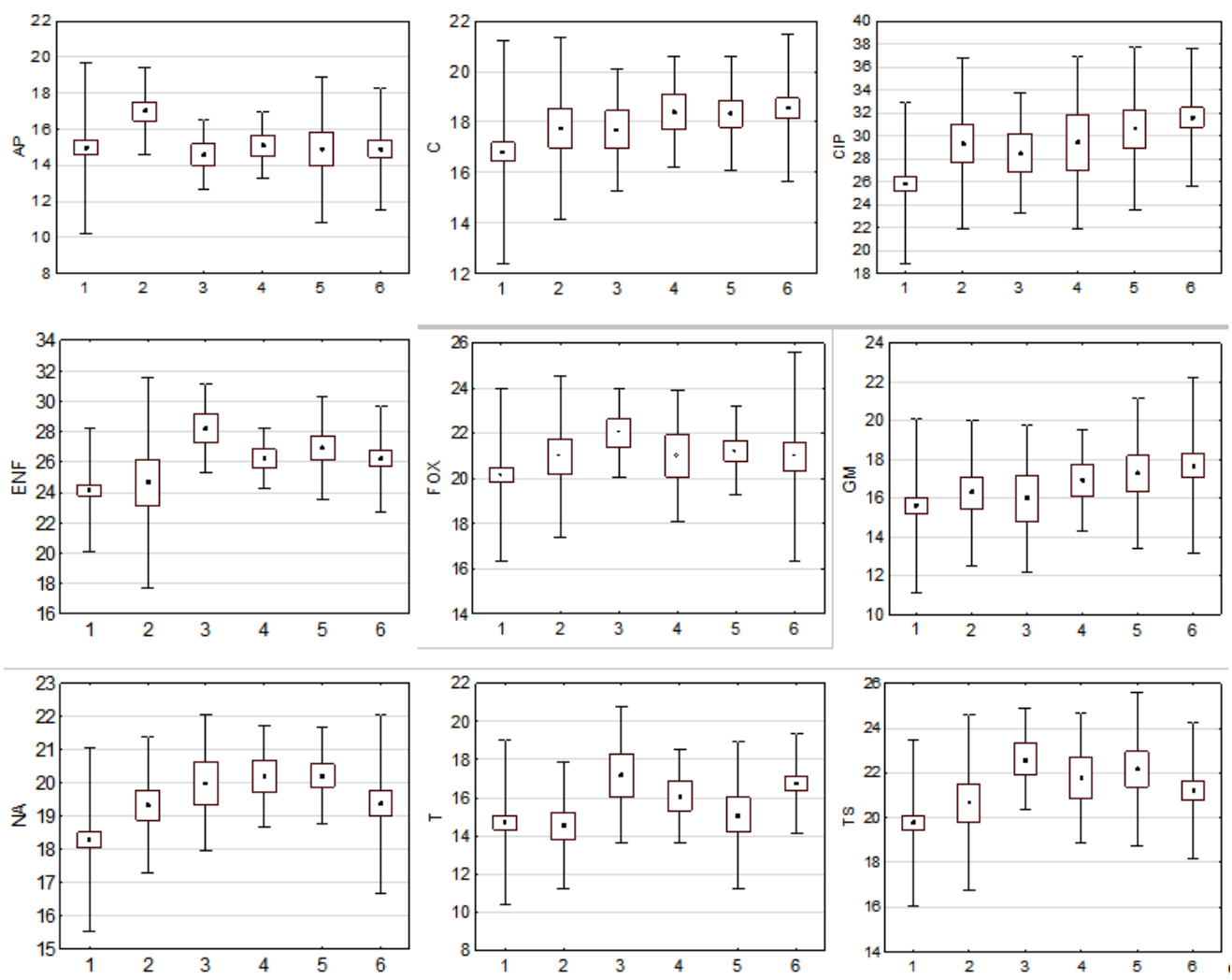

Note: The vertical axis represents the zone diameter of inhibition $(\mathrm{mm})$ and the horizontal axis represents the different sources of isolates as follows, pigeon faecal isolates (1), RHRW isolates from JHB S1 (2), JHB S2(3), PTA S3 (4) PTA S2 (5) and PTA S1 (6). The antibiotics represented are ampicillin (Ap), chloramphenicol (C), ciprofloxacin (Cip), enrofloxacin (Enf), cefoxitin (Fox), gentamicin (Gm), nalidixic acid (Na) tetracycline (T) and cotrimoxazole (Ts).

Figure 1: The variability in antibiotic resistance/susceptibility patterns for where significant differences observed between the different sources: each box plot represents the mean (dot) +/- standard error (bottom and top of box) $+/$ standard deviation (whiskers)

\section{Correlation test}

Table 4 shows the comparison of percentages of antibiotic resistant $E$. coli isolated from RHRW sources in Johannesburg and Pretoria, and from pigeon faeces. No significant correlation was observed between Johannesburg and Pretoria sources $(r \leq 0.611, p<0.01)$, although there was a relatively high correlation between source sites from the same area $(r \geq 0.707)$, except for isolates from PTA S3 (r=0.6). This PTA S3 site had no significant correlation to any other site. However, 
all other RHRW sites were significantly correlated to the averages from RHRW and bird sources $(\mathrm{r} \geq 7.17)$ except for the JHB S1 $(r=0.684)$ source with RHRW source. Antibiotic resistance profiles of pigeon isolates had a wide diversity representation, with the result that, relatively high correlation rates existed between bird and individual RHRW sites. However, individual RHRW sites had relatively limited diversity unique to individual sites, resulting in lower correlation rates between sites.

Table 4: Pearson's product moment correlation coefficient between different sites, areas and sources of Escherichia coli antibiotic resistance profiles

\begin{tabular}{|l|cccccccc|}
\hline \multicolumn{1}{|c}{} & JHB S1 & JHB S2 & JHB & PTA S1 & PTA S2 & PTA S3 & PTA & RHRW Total \\
\hline JHB S1 & 1 & & & & & & & \\
JHB S2 & 0.514 & 1 & & & & & & \\
JHB & $0.970^{* *}$ & $0.707^{*}$ & 1 & & & & & \\
PTA S1 & 0.41 & $0.611^{*}$ & 0.511 & 1 & & & & \\
PTA S2 & 0.541 & $0.611^{*}$ & $0.618^{*}$ & $0.748^{* *}$ & 1 & & \\
PTA S3 & -0.225 & -0.047 & -0.198 & 0.573 & 0.339 & 1 & & \\
PTA & 0.425 & $0.606^{*}$ & 0.522 & $0.983^{* *}$ & $0.848^{* *}$ & $0.600^{*}$ & 1 & \\
RHRW Total & $0.684^{*}$ & $0.721^{* *}$ & $0.768^{* *}$ & $0.930^{* *}$ & $0.868^{* *}$ & 0.376 & $0.947^{* *}$ & 1 \\
Pigeon faeces & $0.717^{* *}$ & $0.835^{* *}$ & $0.827^{* *}$ & $0.792^{* *}$ & $0.899^{* *}$ & 0.193 & $0.838^{* *}$ & $0.940^{* *}$ \\
\hline
\end{tabular}

Significance of t-test $; * 0.05$ and $* * 0.01$ level (1-tailed).

\section{Antibiotic resistance phenotypes}

Antibiotic resistance (AR) phenotypes were determined for E. coli isolated from RHRW and faeces obtained from storage tanks and urban pigeons, respectively (Table 4). Figure 2 and Table 5 shows the observed antibiotic resistant percentages of isolates by their sources for 1-5 and 7 antibiotics. The highest number of phenotypes was observed for single antibiotics (7), whereas 4 , 7, 5, 1 and 1 multiple antibiotic resistance (MAR) phenotypes were detected for combinations of 2, 3, 4, 5 and 7 antibiotics, respectively. No single AR phenotypes were detected for 
Table 5: Antibiotic resistance phenotypes of Eschericha coli isolated from pigeon faeces and roof harvested rainwater obtained from rainwater harvesting tanks*

\begin{tabular}{|c|c|c|c|c|c|c|c|c|c|c|}
\hline \multirow{3}{*}{ Resistance Phenotype } & \multicolumn{8}{|c|}{ Source } & \multicolumn{2}{|c|}{ Overall } \\
\hline & \multicolumn{2}{|c|}{ Pretoria } & \multicolumn{2}{|c|}{ Johannesburg } & \multicolumn{2}{|c|}{ RHRW } & \multicolumn{2}{|c|}{ Birds } & & \\
\hline & $\mathrm{n}$ & $\%$ & $\mathrm{n}$ & $\%$ & $\mathrm{n}$ & $\%$ & $\mathrm{n}$ & $\%$ & $\mathrm{n}$ & $\%$ \\
\hline A & 3 & 3.8 & 1 & 3.1 & 4 & 3.6 & 1 & 0.8 & 5 & 2.1 \\
\hline Ak & 2 & 2.6 & 1 & 3.1 & 3 & 2.7 & 6 & 4.5 & 9 & 3.7 \\
\hline Ap & 5 & 6.4 & 2 & 6.3 & 7 & 6.4 & 7 & 5.3 & 14 & 5.8 \\
\hline Cip & 1 & 1.3 & 0 & 0 & 1 & 0.9 & 2 & 1.5 & 3 & 1.2 \\
\hline $\mathrm{Gm}$ & 1 & 1.3 & 1 & 3.1 & 2 & 1.8 & 6 & 4.5 & 8 & 3.3 \\
\hline $\mathrm{Na}$ & 1 & 1.3 & 0 & 0 & 1 & 0.9 & 2 & 1.5 & 3 & 1.2 \\
\hline $\mathrm{T}$ & 3 & 3.8 & 6 & 18.8 & 9 & 8.2 & 6 & 4.5 & 15 & 6.2 \\
\hline A-Fox & 2 & 2.6 & 0 & 0 & 2 & 1.8 & 1 & 0.8 & 3 & 1.2 \\
\hline Gm-Ak & 1 & 1.3 & 2 & 6.3 & 3 & 2.7 & 10 & 7.6 & 13 & 5.4 \\
\hline Gm-Ap & 2 & 2.6 & 1 & 3.1 & 3 & 2.7 & 2 & 1.5 & 5 & 2.1 \\
\hline Ak-Ap & 2 & 2.6 & 0 & 0 & 2 & 1.8 & 2 & 1.5 & 4 & 1.7 \\
\hline$A-C-T$ & 0 & 0 & 0 & 0 & 0 & 0 & 6 & 4.5 & 6 & 2.5 \\
\hline A-Ap-Fox & 2 & 2.6 & 0 & 0 & 2 & 1.8 & 3 & 2.3 & 5 & 2.1 \\
\hline A-Ap-T & 2 & 2.6 & 0 & 0 & 2 & 1.8 & 2 & 1.5 & 4 & 1.7 \\
\hline A-Ap-TC & 1 & 1.3 & 0 & 0 & 1 & 0.9 & 3 & 2.3 & 4 & 1.7 \\
\hline A-Ak-Gm & 3 & 3.8 & 0 & 0 & 3 & 2.7 & 2 & 1.5 & 5 & 2.1 \\
\hline Ak-Ap-Cip & 1 & 1.3 & 1 & 3.1 & 2 & 1.8 & 4 & 3 & 6 & 2.5 \\
\hline Ak-Ap-Gm & 2 & 2.6 & 0 & 0 & 2 & 1.8 & 2 & 1.5 & 4 & 1.7 \\
\hline Ak- Gm-Enf- Ap & 0 & 0 & 2 & 6.3 & 2 & 1.8 & 1 & 0.8 & 3 & 1.2 \\
\hline Ak- Gm-Enf- Cro & 0 & 0 & 2 & 6.3 & 2 & 1.8 & 1 & 0.8 & 3 & 1.2 \\
\hline Ak-Gm-Ap-A & 3 & 3.8 & 1 & 3.1 & 4 & 3.6 & 0 & 0 & 4 & 1.7 \\
\hline Ak-Gm-Cip-T & 1 & 1.3 & 1 & 3.1 & 2 & 1.8 & 9 & 6.8 & 11 & 4.5 \\
\hline Gm-Cip-Fox-A & 0 & 0 & 0 & 0 & 0 & 0 & 5 & 3.8 & 5 & 2.1 \\
\hline Ak-Enf-Gm-Ap-T & 0 & 0 & 0 & 0 & 0 & 0 & 4 & 3 & 4 & 1.7 \\
\hline A-Cip-Gm-Ap-Cro-Fox-Na & 0 & 0 & 0 & 0 & 0 & 0 & 2 & 1.5 & 2 & 0.8 \\
\hline Susceptible & 40 & 51.3 & 11 & 34.4 & 51 & 46.4 & 43 & 32.6 & 94 & 38.8 \\
\hline
\end{tabular}

Note: Sampling sites were grouped by their origin to form the Pretoria and Johannesburg areas which were also combined to form the roof harvested rainwater source. Percentages were calculated by dividing the number of confirmed antibiotic resistant E. coli in a particular area or source by the total number of isolates tested for the particular area or source. 


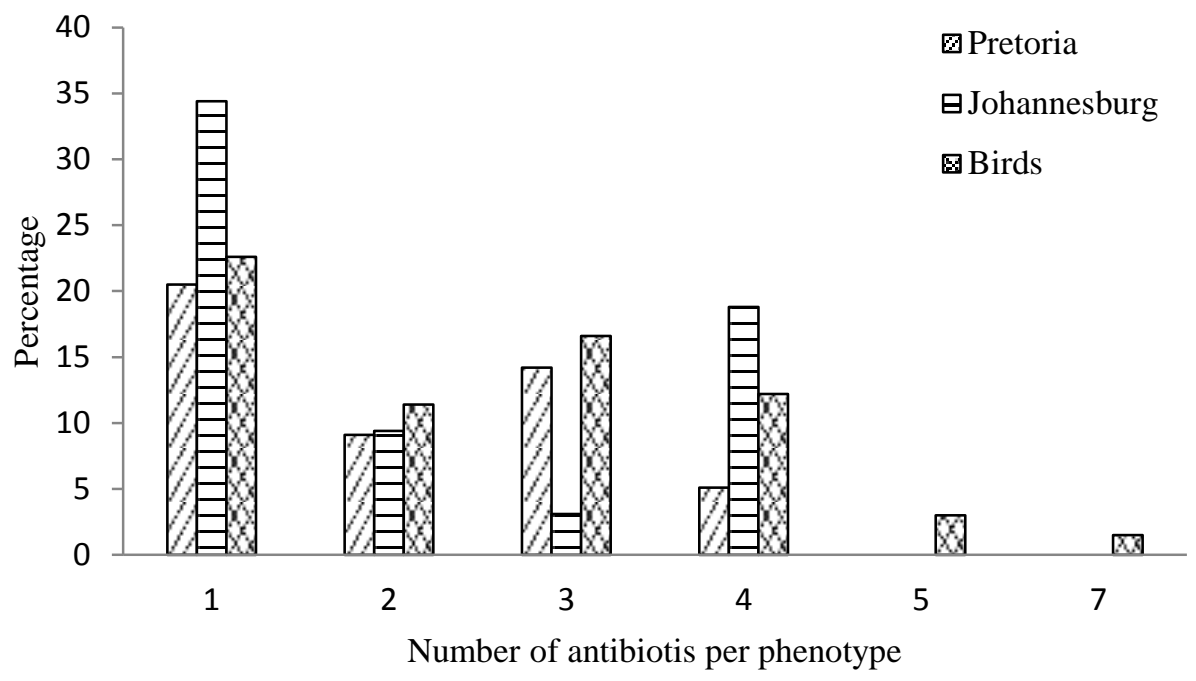

Figure 2: Abundance percentages of the observed phenotypes per groups of antibiotics by their sources

chloramphenicol, ceftriaxone, gentamicin, cefoxitin and cotrimoxazole, although, they were detected in MAR phenotypes. The most abundant resistance phenotype was on single antibiotics with 34.4 , 20.5and $22.6 \%$ of isolates from JHB, PTA and pigeon faeces being resistant. For these resistance percentages tetracycline $(6.2 \%)$ and ampicillin $(5.8 \%)$ were the most abundant, considering all isolates. A higher proportion of isolates from JHB (18.8\%) had tetracycline resistance phenotype compared to those from Pretoria (3.8\%) and pigeon faeces (4.5\%). However, isolates of relatively the same proportion (5.3-6.4\%) from all sources were resistant to ampicillin. The least abundant single antibiotic resistance phenotype (1.2\%) was observed for ciprofloxacin and nalidixic acid on isolates from Pretoria and pigeon faeces.

Resistance to two antibiotics was relatively similar (9.1-9.4\%) among RHRW sources, although bird isolates had a relatively higher proportion (15.9\%) resistant to the same number of antibiotics. The A-Fox and Ak-Ap combinations were not detected in isolates from Johannesburg, although they were present in isolates from Pretoria and pigeon faeces. The most dominant phenotype of resistance to two antibiotics was Ak-Gm (5.4\%). A relatively higher proportion of isolates with this phenotype was detected in pigeon faeces (7.6\%) and Johannesburg area. A relatively higher proportion of isolates from Pretoria (14.2\%) and pigeon 
faeces $(12.1 \%)$ had MAR for combinations of three antibiotics compared to those from Johannesburg (3.1\%). The most abundant three antibiotic phenotype was A-Ak-Gm with prevalence's ranging from 3.1- 3.8\% for all sources. Of the six MAR phenotypes to combinations of three antibiotics, only 1 (Ak-Ap-Cip) was detected from Johannesburg isolates, whereas all the six phenotypes were detected in isolates from Pretoria and pigeon faeces. Furthermore the A-C-T phenotype was detected in isolates from pigeon faeces $(4.5 \%)$ only.

The highest MAR observed for combinations of four antibiotics was for isolates from Johannesburg (18.8\%) and pigeon faeces $15.2 \%$, although only $5.1 \%$ of Pretoria isolates were resistant to the same number of antibiotics. The most abundant resistance phenotype to four antibiotics (4.5\%) was Ak-Gm-Cip-T. This phenotype was dominated by isolates from birds (6.8\%) with Pretoria and Johannesburg isolates having low proportions of $1.3 \%$ and $3.1 \%$ respectively. Similar phenotypes were observe for the Ak-Enf-Gm-Ap and Ak-Enf-Gm-Cro antibiotic combinations for isolates from Johannesburg, (6.3\%) but were not detected in isolates from Pretoria. The four (Gm-Cip-Fox-A), 5 (Ak-Enf-Gm-Ap-T) and seven (A-Cip-Gm-Ap-CroFox-Na) were detected in four, five and two isolates from birds only, respectively. However, the phenotypes Ak-Enf-Gm-Ap and Ak-Enf-Gm-Cro were not detected from Pretoria isolates, whereas Ak-Gm-Ap-A was only detected in RHRW sources.

\section{Discussion}

Bird populations sympatric to areas inhabited by people and areas with a high density of livestock have been reported to be colonised with antibiotic resistant E. coli strains possibly selected by the antibiotic practice in humans and domestic animals (Marques et al. 2007; Silva et al. 2009). In particular, urban pigeons (Columba livia) come into close contact with humans and other animals, and are considered to be important reservoirs and vectors of pathogenic and antibiotic resistant bacterial strains (Silva et al. 2009). The adaptation of these birds to urban environments, the absence of natural predators and availability of food enables them to multiply extensively and become a significant source of faecal pollution (Marques et al. 2007). The presence of pigeon faeces in urban environments may contribute to the spread of infectious 
agents through the dispersion of wind-dried dropping particles (Marques et al. 2007; de Oliveira and Pinhata 2008).

We therefore hypothesised that if birds are the major source of faecal pollution, then the antibiotic resistance profiles between RHRW isolates from PTA S1 and pigeon faecal isolates would be similar. Since the birds are mobile, we included a site (PTA S2) $5 \mathrm{~km}$ away, that had limited bird interference and another (PTA S3) that was 20km away, of which had abundant trees and bird populations. Furthermore, to evaluate diversity and probable similarity in faecal source of contamination we included two sites (JHB S2and JHB S1) located in Thembisa, Johannesburg, about $54 \mathrm{~km}$ away from Pretoria sites.

Generally, in antibiotic resistance BST, a database of antibiotic resistance patterns from known sources within an area is needed for isolates comparison. In this method sample level analysis or isolate-level analysis can be used. However, if it was assumed that a sample came from a single major source, as was the case in this study, then sample level analysis can be used (Harwood et al. 2003). Nevertheless, it is very unlikely that a RHRW sample would contain only one source of contamination. Consequently, we also used isolate-level analysis which is suitable for analysis if samples are assumed to be contaminated by more than one source (Wiggins et al. 2003). We assumed that pigeon faecal isolated were representative of the major faecal sources including cows and chickens, since we had observed them feeding in close contact to faecal material from these animals. It should be noted that several studies on antibiotic resistance analysis (ARA) have cited it as a useful tool in assessing contamination sources with average rates of correct classification ranging from 62 to 84\%, (Harwood et al. 2003; Wiggins et al. 2003).

\section{Antibiotic resistance profiles of samples}

In this study, antibiotic resistance was observed in E. coli isolates from all RHRW sites and bird faecal samples. The most frequently encountered form of resistance in all samples was to ampicillin (26.9\%), gentamicin (26\%), amoxicillin (25.2\%), tetracycline (18.2\%), and amikacin 
(17.8\%) (Table 2). Most of these antibiotics have been widely used for therapeutic purposes against bacterial infections in humans and animals as well as growth promoters in agriculture and aquaculture (Khachatourians 1998). Similar multidrug resistance phenotypes of E. coli isolated from water sources have been reported worldwide (Watkinson et al. 2007).

The observation of relatively high antibiotic resistance percentages (Table 2) to similar antibiotics for $E$. coli from RHRW and birds, suggest birds to be the source of RHRW contamination. Similarly the observed correlation between pigeon faecal isolates and individual RHRW sites from both Pretoria and Johannesburg were all significant $(\mathrm{r} \geq 0.717 ; p \leq 0.01)$, except for isolates from PTA S3 ( $r=0.6)$ in Pretoria. Isolates from the PTA S3 sites had no significant correlation to any of the other RHRW sites. This can be explained by site specific factors such as the presence of different species of birds or animals that may harbour E. coli with variant antibiotic resistance profiles. When we asked people residing at this site, about birds common in surrounding trees, no mention was given of pigeons. It is also important to note that except for this site we had seen pigeons in surrounding environments of all the other sites during sample collection. The PTA S3 site is located in a suburban area where garbage is efficiently collected and is not near garbage dump site; hence there is a limited supply of food. On the contrary the PTA S1 is situated on a farm near cattle feed lot where thousands of pigeons come to feed. Although the PTA S2 site which is situated about $5 \mathrm{~km}$ from PTA S1, is on the second floor clear of trees, windblown bird dropping particles can explain the similarity. On the other hand, sites in Johannesburg are located in Thembisa, a high density township with a limited number of trees but abundant public refuse dump containers, and it was common to see dumped food and pigeons along the streets.

Isolates from birds had a relatively higher proportion of antibiotic resistance than those from RHRW tanks, with the most significant differences being noted in resistance to gentamicin (12.3\%), tetracycline (9.8\%), chloramphenicol (6.5\%), and amikacin (4.2\%) suggesting E. coli sources other than bird droppings only. This was supported by finding from Kruskal Wallis nonparametric tests of antibiotic resistance prevalence between isolates from RHRW and pigeon 
faeces, and between different RHRW sites, where significant differences $(p \leq 0.05)$ in 8 antibiotics were noted between all RHRW sites and pigeons and only one antibiotic between RHRW sites only. Hence it can be suggested that there may be other sources of faecal contamination at play, which harbour E. coli with less AR prevalence. Probable sources of these E. coli are natural environmental habitats, other species of birds, small animals such as rats and dust particles with E. coli populations that are not as exposed to antibiotic as are other domestic animals.

Given the erratic nature of rainfall in Gauteng and the amount of sun received, dust particles should be a significant factor of RHRW contamination. Previous research on the influence of prevailing air quality in the environment surrounding a rainwater harvesting site, have suggested air quality to play an important role in influencing the microbial quality of rainwater (Evans et al. 2006; Kaushik et al. 2012). The link between air quality and the microbial quality of rainwater under different weather conditions have been suggested as one of the reasons for discrepancies in reported literature concerning rainwater portability. For instance, research by Kaushik et al., (2012) on rainwater contamination factors that are independent of external sources of contamination such as those encountered with roof- harvesting methods found E. coli to be one of the microorganisms present in fresh rainwater and contributing to its microbial diversity. Furthermore, a study by Evans et al., (2007) on the influence of weather conditions on roof water contamination, found that wind speed and direction had a strong influence on the microbial quality of RHRW.

Similar to our findings, previous research have shown E. coli strains isolated from pigeon faeces to be antibiotic resistant and may reflect the abusive use of such substances in our society (Silva et al. 2009). Pigeons possess a less developed cecum, which is the part of the gastrointestinal tract that harbours the most abundant and diversified microbiota. Hence, it is possible that these microorganisms may not be true inhabitants of pigeon faecal flora. Consequently, it is less likely that these birds could have a permanent gut microbiota with intestinal bacterial species commonly associated with humans (Baele et al. 2002). However, the feeding habits of urban 
pigeons and doves may include garbage from nearby trash cans, which exposes them to contamination with residual antimicrobials or chemicals and medically important bacteria (Rosengren et al. 2009).

Despite the lack of reports on antimicrobial susceptibility patterns of E. coli from RHRW and their comparison to the likely sources of faecal origin, a number of researches have shown increasing resistance to tetracycline, ampicillin and gentamicin, with resistance at lower levels to cotrimoxazole, nalidixic acid chloramphenicol enrofloxacin cefoxitin and ciprofloxacin, similar to our findings (Harwood et al. 2003; Wiggins et al. 2003; Silva et al. 2009).

\section{Multiple antibiotic resistance patterns}

High prevalence of MAR were noted on combinations of four antibiotics in isolates from JHB (18.8\%) and birds $15.2 \%$ suggesting the JHB sites to be highly impacted by pigeon droppings. However, the low prevalence (5.1\%) observed for PTA sites on the same number of MAR, suggests that birds may not be the only source of contamination for these sites. The most abundant resistance phenotype to four antibiotics (Ak-Gm-Cip-T) was dominated by isolates from birds (6.8\%) with Pretoria and Johannesburg isolates having low proportions of 1.3 and $3.1 \%$ respectively.

It is important to note that most of the MAR observed included resistance to an aminoglycoside (Gentamicin (Gm) or amikacin (Ak) or both). Gentamicin, was originally approved for use in the USA in 1963 (Walsh, 2003) and is widely used in the poultry industry. In our study, 64.4\% (47/73) of gentamicin-resistant $E$. coli isolates were multidrug resistant ( $\geq 3$ classes of drugs). Forty three percent (32/73) were resistant to $\geq 4$ antibiotics, including $54.8 \%$ (40/73) to amikacin, $31.5 \%$ (23/73) to ampicillin, and $20.5 \%$ (15/73) to tetracycline and $32.9 \% 24 / 73$ to ciprofloxacin.

Relatively high prevalence of resistance to gentamicin by both bird droppings and RHRW isolates can be explained by findings from previous research which suggested that selective 
pressure by heavy antibiotic usage may not be responsible for all common aminoglycoside resistance (Gardner et al. 1969). It has also been shown that E. coli with aminoglycoside can multiply and persist in the gastrointestinal tract of poultry in the absence of selective pressure by antibiotics (Guillot et al. 1977). Furthermore, several genes that confer multiple-aminoglycoside resistance in E. coli have been reported (Davis et al. 2010). Hence, the observed prevalence in aminoglycoside resistance should not be surprising.

Other antibiotics of importance to which resistance was observed include tetracycline and chloramphenicol to a lesser extent. Tetracycline was approved in the USA in 1948 (Walsh and others 2003), and has widely been used in therapy and to promote feed efficiency in animal production systems. Persistence of tetracycline resistance in animal coliforms was first reported a decade after it was no longer used in animal feed or for treatment (Langlois et al. 1986). We commonly found co-resistance for tetracycline with amoxicillin, gentamicin, ciprofloxacin, cefoxitin, ampicillin, and chloramphenicol, as in other studies (Roberts 2005; Kozak et al. 2009).

Another antibiotic, chloramphenicol, was approved in 1947 and was strictly used for human clinical purposes. However, florfenicol, a closely related drug, was approved for treatment of respiratory diseases in cattle (USDA, 2010). Consequently persistence of chloramphenicol resistance in E. coli has been observed (Sayah et al. 2005; Tadesse et al. 2012). The flo gene which mediates florfenicol resistance, confers nonenzymatic cross-resistance to chloramphenicol and might select for nascent resistance in recent strains (Tadesse et al. 2012). It is important to note that only a small number of known chloramphenicol resistance genes mediate resistance to florfenicol. For instance, chloramphenicol-resistant strains in which resistance is exclusively based on activity of chloramphenicol acetyltransferases do not show resistance to florfenicol (Schwarz et al. 2004). 


\section{Conclusion and recommendations for further studies}

This study provides foundational information on the antibiotic resistance diversity of $E$. coli present in RHRW. This lays the groundwork for understanding the multiple probable sources of contamination, and chances for remediation. These data show that urban pigeons, the most likely source of RHRW contamination are reservoirs of multiple antibiotic resistant bacteria. This is important, as RHRW is presumed safe and is generally consumed without prior treatment. This is of serious concern given that approximately $20 \%$ of the South African population is HIV positive (Shisana et al. 2010). Since the pathological implications of infection by E. coli harbouring pathogenic elements and multidrug resistance, especially on individuals with suppressed immune systems are devastating.

Currently, there is ongoing work to evaluate temporal and special variation in RHRW quality for different rainwater harvesting systems in various rural, urban and informal settlements in South Africa and its suitability for domestic use (WRC, 2012). This work will provide more definitive data on critical factors for sustainable RWH practices suitable for the different communities in South Africa. However, more work still need to be done to evaluate the presence of antibiotic resistance genetic determinants and the presence of various pathogenic elements in the isolates. Further, work should also include not only birds, but all probable sources of contamination including weather factors such as wind and other sources of faecal pollution including domestic animals. Other microbes of importance such as Salmonella, Campylobacter, Listeria, enterococci and Yesinia should be included, together with microbial diversity characterisation techniques such as repetitive palindromic sequence (rep) PCR, single nucleotide polymorphism typing, phylogenetic and clade grouping. This will give more comprehensive data from which a relatively accurate estimation of the risks can be made, probable sources of contamination be determined and mitigation responses be appropriated with a better degree of accuracy and certainty. 


\section{Acknowledgements}

This study was undertaken as part of a Water Research Commission (WRC) unsolicited project: "Evaluation of the risks associated with the use of rainwater harvested from roofs, for domestic use and, homestead food gardens; and groundwater for domestic use and livestock watering (WRC Project No K5/2175, Water Research Commission, 2012).

\section{References}

Ahmed, W., Gardner, T., \& Toze, S. (2011). Microbiological quality of roof-harvested rainwater and health risks: A review. Journal of Environmental Quality, 40(1), 13-21. doi:10.2134/jeq2010.0345

Ahmed, W., Hodgers, L., Masters, N., Sidhu, J. P. S., Katouli, M., \& Toze, S. (2011). Occurrence of intestinal and extraintestinal virulence genes in Escherichia coli isolates from rainwater tanks in Southeast Queensland, Australia. Applied and Environmental Mcrobiology, 77(20), 7394-7400. doi:10.1128/AEM.06047-11

Ahmed, W., Huygens, F., Goonetilleke, A., \& Gardner, T. (2008). Real-Time PCR Detection of Pathogenic Microorganisms in Roof-Harvested Rainwater in Southeast Queensland, Australia. Applied and Environmental Microbiology, 74(17), 5490-5496. doi:10.1128/AEM.00331-08

Anderson, M. A., Whitlock, J. E., Valerie, J., \& Harwood, V. J. (2006). Diversity and Distribution of Escherichia coli Genotypes and Antibiotic Resistance Phenotypes in Feces of Humans, Cattle, and Horses Diversity and Distribution of Escherichia coli Genotypes and Antibiotic Resistance Phenotypes in Feces of Humans, Cattl. Applied and Environmental Microbiology, 72(11), 6914-6922. doi:10.1128/AEM.01029-06

Antai, S. P. (1987). Incidence of Staphylococcus aureus, coliforms and antibiotic-resistant strains of Escherichia coli in rural water supplies in Port Harcourt. The Journal of applied bacteriology, 62(4), 371-375. 
Anyadike, E. A., \& Obeta, R. N. C. (2012). Differential Susceptibility of Roof Catchments to Rainwater Contaminants in Oil and Non-Oil Producing Areas of Akwa Ibom State, Nigeria . Department of Geography, University of Nigeria. Canadian Journal on Scientific and Industrial Research, 3(4), 184-192.

Baele, M., Devriese, L. A., Butaye, P., \& Haesebrouck, F. (2002). Composition of enterococcal and streptococcal flora from pigeon intestines. Journal of Applied Microbiology, 92(2), 348-351.

Bittar, F., Ouchenane, Z., Smati, F., Raoult, D., \& Rolain, J.-M. (2009). MALDI-TOF-MS for rapid detection of staphylococcal Panton-Valentine leukocidin. International journal of antimicrobial agents, 34(5), 467-70. doi:10.1016/j.ijantimicag.2009.03.017

Clesceri, L. S., Greenberg, A. E., \& Eaton, A. D. (1998). Standard methods for the examination of water and wastewater. American Public Health Association, Washington, DC, 5-18.

Dalla-costa, L. M., Irino, K., Rodrigues, J., Rivera, I. N. G., \& Trabulsi, L. R. (1998). Characterisation of diarrhoeagenic Escherichia coli clones by ribotyping and ERIC-PCR, Journal of Medical Microbiology, 47, 227-234.

Davis, M. A., Baker, K. N. K., Orfe, L. H., Shah, D. H., Besser, T. E., \& Call, D. R. (2010). Discovery of a gene conferring multiple-aminoglycoside resistance in Escherichia coli. Antimicrobial agents and chemotherapy, 54(6), 2666-2669.

De Oliveira, A. J., \& Pinhata, J. M. (2008). Antimicrobial resistance and species composition of Enterococcus spp. isolated from waters and sands of marine recreational beaches in Southeastern Brazil. Water Research, 42(8), 2242-2250.

Dolejska, M., Šenk, D., Č́ížek, A., Rybalvríková, J., Sychra, O., \& Literak, I. (2008). Antimicrobial resistant Escherichia coli isolates in cattle and house sparrows on two Czech dairy farms. Research in veterinary science, 85(3), 491-494. 
Donovan, E. P., Staskal, D. F., Unice, K. M., Roberts, J. D., Haws, L. C., Finley, B. L., \& Harris, M. A. (2008). Risk of gastrointestinal disease associated with exposure to pathogens in the sediments of the Lower Passaic River. Applied and Environmental Microbiology, 74(4), 1004-1018.

Evans, C. A., Coombes, P. J., \& Dunstan, R. H. (2006). Wind, rain and bacteria: The effect of weather on the microbial composition of roof-harvested rainwater. Water research, 40(1), 37-44.

Evans, C. A., Coombes, P. J., Dunstan, R. H., \& Harrison, T. (2007). Identifying the major influences on the microbial composition of roof harvested rainwater and the implications for water quality. Water Science Technology, 55(4), 245-253. doi:10.2166/wst.2007.115

Gardner, P., Smith, D., Beer, H., \& Moellering Jr, R. (1969). Recovery of resistance (R) factors from a drug-free community. The Lancet, 294(7624), 774-776.

Goering, R. V. (2010). Infection, Genetics and Evolution Pulsed field gel electrophoresis : A review of application and interpretation in the molecular epidemiology of infectious disease. “Infection, Genetics and Evolution”, 10(7), 866-875. doi:10.1016/j.meegid.2010.07.023

Guillot, J. F., Chaslus-Dancla, E., \& Lafont, J. P. (1977). Spontaneous implantation of antibioticresistant Enterobacteriaceae in the digestive tract of chickens in the absence of selective pressure. Antimicrobial Agents and Chemotherapy, 12(6), 697-702.

Harwood, V. J., Butler, J., Parrish, D., \& Wagner, V. (1999). Isolation of fecal coliform bacteria from the diamondback terrapin (Malaclemys terrapin centrata). Applied and Environmental Microbiology, 65(2), 865-867.

Harwood, V., Wiggins, B., Hagedorn, C., Ellender, R., Gooch, J., Kern, J., ... Thompson, B. (2003). Phenotypic library-based microbial source tracking methods: efficacy in the California collaborative study. Journal of Water and Health, 1, 153-166. 
Kahinda, J. M., Taigbenu, A. E., Boroto, J. R., \& Mwenge Kahinda, J. (2007). Domestic rainwater harvesting to improve water supply in rural South Africa. Physics and Chemistry of the Earth, 32(15-18), 1050-1057. doi:10.1016/j.pce.2007.07.007

Kaushik, R., Balasubramanian, R., \& de la Cruz, A. A. (2012). Influence of air quality on the composition of microbial pathogens in fresh rainwater. Applied and Environmental Microbiology, 78(8), 2813-8. doi:10.1128/AEM.07695-11

Khachatourians, G. G. (1998). Agricultural use of antibiotics and the evolution and transfer of antibiotic-resistant bacteria. Canadian Medical Association Journal, 159(9), 1129-1136.

Kinge, W. C. N., Njie, N. C., \& Kawadza, T. D. (2010). Antibiotic resistance profiles of Escherichia coli isolated from different water sources in the Mmabatho locality, North-West Province, South Africa. South African Journal of Science, 106(1), 44-49. doi:10.4102/sajs.v106i1/2.14

Kozak, G. K., Pearl, D. L., Parkman, J., Reid-Smith, R. J., Deckert, A., \& Boerlin, P. (2009). Distribution of sulfonamide resistance genes in Escherichia coli and Salmonella isolates from swine and chickens at abattoirs in Ontario and Quebec, Canada. Applied and Environmental Microbiology, 75(18), 5999-6001.

Langlois, B. E., Dawson, K. A., Cromwell, G. L., \& Stahly, T. S. (1986). Antibiotic resistance in pigs following a 13 year ban. Journal of Animal Science, 62(Supplement 3), 18-31.

Marques, S. M. T., de Cuadros, R. M., Silva, C. J., \& Baldo, M. (2007). Parasites of pigeons (Columba livia) in urban areas of lages, Southern Brazil. Parasitol Latinoam, 62(3-4), 183187.

Meays, C. L., Broersma, K., Nordin, R., \& Mazumder, A. (2004). Source tracking fecal bacteria in water: a critical review of current methods. Journal of Environmental Management, 73(1), 71-79. doi:10.1016/j.jenvman.2004.06.001 
Mohapatra, B. R., Broersma, K., \& Mazumder, A. (2007). Comparison of five rep-PCR genomic fingerprinting methods for di $;$ erentiation of fecal Escherichia coli from humans, poultry and wild birds. FEMS Microbiology Letters, 277, 98-106. doi:10.1111/j.15746968.2007.00948.x

Mohapatra, B. R., \& Mazumder, A. (2008). Comparative efficacy of five different rep-PCR methods to discriminate Escherichia coli populations in aquatic environments. Water Science and Technology, 58.3, 537-547. doi:10.2166/wst.2008.424

Myoda, S., Carson, C., Fuhrmann, J., Hahm, B., Hartel, P., Yampara-Iquise, H., ... others. (2003). Comparison of genotypic-based microbial source tracking methods requiring a host origin database. $J$ Water Health, 1, 167-180.

Pinto, L., Poeta, P., Radhouani, H., Coelho, C., Carvalho, C., Rodrigues, J., ... Igrejas, G. (2011). Proteomic study in an Escherichia coli strain from seagulls of the Berlengas Natural Reserve of Portugal. Genetics, 1(1), 36-41. doi:10.5584/jiomics.v1i1.19

Power, M. L., Littlefield-Wyer, J., Gordon, D. M., Veal, D. A., \& Slade, M. B. (2005). Phenotypic and genotypic characterization of encapsulated Escherichia coli isolated from blooms in two Australian lakes. Environmental Microbiology, 7(5), 631-640.

Radimersky, T., Frolkova, P., Janoszowska, D., Dolejska, M., Svec, P., Roubalova, E., ... Literak, I. (2010). Antibiotic resistance in faecal bacteria (Escherichia coli, Enterococcus spp.) in feral pigeons. Journal of applied microbiology, 109(5), 1687-1695.

Roberts, M. C. (2005). Update on acquired tetracycline resistance genes. FEMS microbiology letters, 245(2), 195-203.

Romanus, I. I., Eze, A. T., Egwu, O. A., Felicitas, A. N., \& Chidiebube, N. A. (2011). Comparison of matrix-assisted laser desorption ionization-time of flight mass spectrometry ( maldi-tof ms ) with conventional culture and biochemical method of bacteria identification to species level. Journal of Medical Laoratory and Diagnosis, 2(1), 1-4. 
Rosengren, L. B., Waldner, C. L., \& Reid-Smith, R. J. (2009). Associations between antimicrobial resistance phenotypes, antimicrobial resistance genes, and virulence genes of fecal Escherichia coli isolates from healthy grow-finish pigs. Applied and Environmental Microbiology, 75(5), 1373-1380.

Sayah, R. S., Kaneene, J. B., Johnson, Y., \& Miller, R. (2005). Patterns of antimicrobial resistance observed in Escherichia coli isolates obtained from domestic- and wild-animal fecal samples, human septage, and surface water. Applied and Environmental Microbiology, 71(3), 1394-404. doi:10.1128/AEM.71.3.1394-1404.2005

Sazakli, E., Alexopoulos, A., \& Leotsinidis, M. (2007). Rainwater harvesting, quality assessment and utilization in Kefalonia Island, Greece. Water research, 41(9), 2039-2047.

Schwarz, S., Kehrenberg, C., Doublet, B., \& Cloeckaert, A. (2004). Molecular basis of bacterial resistance to chloramphenicol and florfenicol. FEMS microbiology reviews, 28(5), 519-542.

Sheludchenko, M. (2011). Development and validation of novel methods for microbial source tracking based on Escherichia coli as an indicator of water quality. Queensland University of Technology.

Shisana, O., Simbay, L., Rehle, T., Zungu, N. P., Zuma, K., Ngogo, N., ... SABSSM III ImplementationTeam. (2010). South African National HIV Prevalence, Incidence, Behaviour and Communication Survey, 2008: The health of our children. Cape Town: HSRC Press.

Silva, V. L., Nicoli, J. R., Nascimento, T. C., \& Diniz, G. C. (2009). Diarrheagenic Escherichia coli Strains Recovered from Urban Pigeons ( Columba livia) in Brazil and Their Antimicrobial Susceptibility Patterns. Current Microbiology, 59, 302-308. doi:10.1007/s00284-009-9434-7

Sivanappan, R. K. (2006). Rain Water Harvesting, Conservation and Management Strategies for Urban and Rural Sectors. In National Seminar on Rainwater Harvesting and Water Management 11-12 Nov. 2006, Nagpu (pp. 1-9). 
Stefanowicz, A. (2006). The Biolog Plates Technique as a Tool in Ecological Studies of Microbial Communities. Polish Journal of Environmental Studies, 15(5), 669-676.

Sung, M., Kan, C. C., Wan, M. W., Yang, C. R., Wang, J. C., Yu, K. C., \& Lee, S. Z. (2010). Rainwater harvesting in schools in Taiwan: system characteristics and water quality. Water Science and Technology, 61(7), 1767-1778.

Tadesse, D. A., Zhao, S., Tong, E., Ayers, S., Singh, A., Bartholomew, M. J. (2012). Antimicrobial Drug Resistance in Escherichia coli from Humans. Emerging Infectious Diseases, 18(5), 741-749.

U.S. Environmental Protection Agency. (2002). Health Risks from Microbial Growth and Biofilms in Drinking Water Distribution Systems. U.S. Environmental Protection Agency Office of Ground Water and Drinking Water Standards and Risk Management, Pennsylvania, Washington DC.

Walsh, C., \& others. (2003). Antibiotics: actions, origins, resistance. American Society for Microbiology (ASM).

Watkinson, A. J., Micalizzi, G. B., Graham, G. M., Bates, J. B., \& Costanzo, S. D. (2007). Antibiotic-resistant Escherichia coli in wastewaters, surface waters, and oysters from an urban riverine system. Applied and Environmental Microbiology, 73(17), 5667-5670.

Wiggins, B. A., Cash, P. W., Creamer, W. S., Dart, S. E., Garcia, P. P., Gerecke, T. M., ... others. (2003). Use of antibiotic resistance analysis for representativeness testing of multiwatershed libraries. Applied and Environmental Microbiology, 69(6), 3399-3405.

Young, J., Yang, J., Han, M., \& Choi, J. (2010). Science of the Total Environment Comparison of the microbiological and chemical characterization of harvested rainwater and reservoir water as alternative water resources. Science of the Total Environment, 408(4), 896-905. doi:10.1016/j.scitotenv.2009.11.001 
Zulkifli, Y., Alitheen, N. B., Son, R., Raha, A. R., Samuel, L., Yeap, S. K., \& Nishibuchi, M. (2009). Random amplified polymorphic DNA-PCR and ERIC PCR analysis on Vibrio parahaemolyticus isolated from cockles in Padang, Indonesia. International Food Research Journal, 16, 141-150. 